\title{
Mitochondria Modify Exercise-Induced Development of Stem Cell-Derived Neurons in the Adult Brain
}

\author{
Kathrin Steib, ${ }^{1}$ Iris Schäffner, ${ }^{1,2}$ Ravi Jagasia, ${ }^{1,3}$ Birgit Ebert, ${ }^{1}$ and D. Chichung Lie ${ }^{1,2}$ \\ ${ }^{1}$ Research Group Adult Neurogenesis and Neural Stem Cells, Institute of Developmental Genetics, Helmholtz Zentrum München, German Research Center \\ for Environmental Health, D-85764 Munich-Neuherberg, Germany, ${ }^{2}$ Institute of Biochemistry, Emil Fischer Center, Friedrich-Alexander-Universität \\ Erlangen-Nürnberg, 91054 Erlangen, Germany, and ${ }^{3}$ F. Hoffmann-La Roche Ltd, CNS Discovery, Pharma Research and Early Development, CH-4070 Basel, \\ Switzerland
}

Neural stem cells in the adult mammalian hippocampus continuously generate new functional neurons, which modify the hippocampal network and significantly contribute to cognitive processes and mood regulation. Here, we show that the development of new neurons from stem cells in adult mice is paralleled by extensive changes to mitochondrial mass, distribution, and shape. Moreover, exercise-a strong modifier of adult hippocampal neurogenesis-accelerates neuronal maturation and induces a profound increase in mitochondrial content and the presence of mitochondria in dendritic segments. Genetic inhibition of the activity of the mitochondrial fission factor dynamin-related protein 1 (Drp1) inhibits neurogenesis under basal and exercise conditions. Conversely, enhanced Drp1 activity furthers exercise-induced acceleration of neuronal maturation. Collectively, these results indicate that adult hippocampal neurogenesis requires adaptation of the mitochondrial compartment and suggest that mitochondria are targets for enhancing neurogenesisdependent hippocampal plasticity.

Key words: Activity; adult hippocampal neurogenesis; exercise; mitochondria; stem cells

\section{Introduction}

The hippocampal dentate gyrus is one of two distinct regions of the adult mammalian brain whose plasticity is dependent on the lifelong generation of new functional neurons (Ming and Song, 2011). The ability of adult-generated dentate granule (DG) neurons to modify the hippocampal network is at least in part the result of their specific connectivity pattern and electrophysiological properties that arise transiently during their maturation $(\mathrm{Ge}$ et al., 2007; Aimone et al., 2011; Sahay et al., 2011; Li et al., 2012; Marín-Burgin et al., 2012).

The development of new functionally integrated DG neurons follows a highly stereotypic sequence of proliferation, differentiation, and maturation steps (Zhao et al., 2008) whose timing can be modulated by experience and hippocampal activity (Zhao et al., 2006; Piatti et al., 2011). Past work identified signaling pathways, and genetic and epigenetic regulators controlling specific

Received Nov. 26, 2013; revised March 27, 2014; accepted April 8, 2014.

Author contributions: K.S., I.S., R.J., B.E., and D.C.L. designed research; K.S., I.S., R.J., and B.E. performed research; K.S., I.S., R.J., B.E., and D.C.L. analyzed data; K.S. and D.C.L. wrote the paper.

K.S. was supported by a doctoral fellowship of the Schering Foundation. Work in the Lie laboratory is supported by a European Young Investigator Award of the European Science Foundation (DFG 858/6-3), the Bavarian Research Networks on Adult Neural Stem Cells "FORNEUROCELL" and on Human Induced Pluripotent Stem Cells "FORIPS," the Helmholtz Alliance for Mental Health in an Ageing Society, the German Federal Ministry for Education and Reserach Network "Cell Based Regenerative Medicine," and the University Hospital Erlangen [Interdisciplinary Center for Clinical Research (IZKF) Grants E12 and E16]. We thank K. Wassmer, F. Gruhn, and M. Ram for excellent technical support. We also thank B. Winner, S. Jessberger, and members of the Lie laboratory for helpful discussions.

The authors declare no competing financial interests.

Correspondence should be addressed to D. Chichung Lie, Institute of Biochemistry, Emil Fischer Center, University Erlangen-Nürnberg, Fahrstrasse 17, 91054 Erlangen, Germany. E-mail: chi.lie@fau.de.

DOI:10.1523/JNEUROSCI.4972-13.2014

Copyright $\odot 2014$ the authors $\quad 0270-6474 / 14 / 346624-10 \$ 15.00 / 0$ developmental steps in adult hippocampal neurogenesis (Hsieh and Eisch, 2010; Hsieh, 2012); moreover, there is increasing insight into the stage-specific molecular signature in adult neurogenesis (Beckervordersandforth et al., 2010; Bracko et al., 2012). In contrast, little is known about the cell-biological processes accompanying and regulating the in vivo development of adultgenerated neurons. As essential cellular functions are compartmentalized into organelles, it is reasonable to assume that organelles undergo remodeling according to the changing demands of the developing neuron and that organelle function influences neuronal development (Sekine et al., 2009).

Mitochondria are vital organelles involved in metabolism, calcium homeostasis, and cell death. Knock-out studies indicate that alterations in mitochondrial distribution and morphology negatively affect neural precursor proliferation (Wakabayashi et al., 2009) and neuronal survival (Ishihara et al., 2009) during embryonic development. Decreased mitochondrial ATP production has been found to impair development of adult-born neurons (Oruganty-Das et al., 2012). In addition, in vitro studies have implied mitochondria distribution, shape, and bioenergetics, in the regulation of neuronal plasticity (Li et al., 2004, 2010; Dietrich et al., 2008; Macaskill et al., 2009; Wang and Schwarz, 2009; Dickey and Strack, 2011; Cheng et al., 2012; Steketee et al., 2012; Bertholet et al., 2013; Courchet et al., 2013). Here, we visualized mitochondria in adult-generated hippocampal neurons under basal conditions, in the context of voluntary exercise, and following genetic modulation of mitochondrial fission and distribution. We report that extensive remodeling of the mitochondrial compartment accompanies neuronal development. Furthermore, we demonstrate that exercise is associated with increased 
mitochondrial biogenesis and mitochondrial distribution, and accelerates neuronal maturation. Finally, we show that modulation of mitochondrial fission and distribution substantially alters exercise-induced maturation of adult-generated hippocampal neurons. These results indicate that regulation of mitochondria is part of the basal and exercise-induced developmental program controlling the formation of new neurons during adulthood.

\section{Materials and Methods}

Animals

All experiments were performed in accordance with the European Communities Council Directive (86/609/EEC). Stereotactic injections of retroviruses into the dentate gyrus of adult mice were approved by the Government of Upper Bavaria. For all experiments, 8-week-old female C57BL/6 mice from Charles River were used. Mice were grouped housed in standard cages under a $12 \mathrm{~h}$ light/dark cycle, and had ad libitum access to food and water. Mice in exercise conditions had ad libitum access to running wheels immediately after retroviral injections.

\section{Retrovirus preparation}

Replication-deficient recombinant murine Moloney leukemia (MML) retroviruses specifically transduce proliferating cells and allow the dating of their birth, and the labeling of precursor cells and their progeny in the adult hippocampal neurogenic lineage (van Praag et al., 2002; Zhao et al., 2006). The CAG red fluorescent protein (RFP) and CAG green fluorescent protein (GFP) recombinant MML retroviruses have been described previously (Zhao et al., 2006; Jagasia et al., 2009). CAG-IRES-mitoGFP and CAG-IRES-mitochondrial Discosoma red (mDsRed) were generated from the pCAG IRES-GFP vector (Jagasia et al., 2009) by replacing the GFP coding sequence with cDNA for mitochondrially targeted GFP or DsRed. For retrovirus-mediated expression of dynamin-related protein 1 (Drp1) and dominant-negative Drp1 ${ }^{\mathrm{K} 38 \mathrm{~A}}$ (dnDrp1; Smirnova et al., 1998; Frank et al., 2001), their respective cDNAs were cloned into the pCAG IRES-mitoGFP or pCAG-IRES-mDsRed to generate pCAGDrp1-IRES-mitoGFP/mDsRed and pCAG-dnDrp1-IRES-mitoGFP/ mDsRed.

Retroviruses were generated as described previously (Tashiro et al., 2006a). Virus-containing supernatant was harvested four times every $48 \mathrm{~h}$ after transfection and concentrated by two rounds of ultracentrifugation. Viral titers were $\sim 5 \times 10^{8}$ colony-forming units $(\mathrm{CFU}) / \mathrm{ml}$.

\section{Stereotactic injections}

For stereotactic injections, mice were deeply anesthetized by injecting a mixture of fentanyl ( $0.05 \mathrm{mg} / \mathrm{kg}$; Janssen-Cilag AG), midazolam $(5 \mathrm{mg} /$ $\mathrm{kg}$; Dormicum, Hoffmann-La Roche), and medetomidine $(0.5 \mathrm{mg} / \mathrm{kg}$; Domitor, Pfizer) dissolved in $0.9 \% \mathrm{NaCl}$. Mice were stereotactically injected at a speed of $250 \mathrm{nl} / \mathrm{min}$ with $0.9 \mu \mathrm{l}$ of the retroviruses with a titer of $2 \times 10^{8} \mathrm{CFU} / \mathrm{ml}$ into the left and right dentate gyri (coordinates from bregma were -1.9 anterior/posterior, \pm 1.6 medial/lateral, -1.9 dorsal/ ventral from dura). For double injections, mice were stereotactically injected with $1 \mu \mathrm{l}$ of a 1:1 retrovirus mixture (titer of $2 \times 10^{8} \mathrm{CFU} / \mathrm{ml}$ for each retrovirus). Anesthesia was antagonized after surgery by injecting the following mixture: buprenorphine $(0.1 \mathrm{mg} / \mathrm{kg}$; Temgesic, Essex Pharma GmbH), atipamezole ( $2.5 \mathrm{mg} / \mathrm{kg}$; Antisedan, Pfizer), and flumazenil $(0.5 \mathrm{mg} / \mathrm{kg}$; Anexate, Hexal AG) dissolved in $0.9 \% \mathrm{NaCl}$.

\section{Tissue processing}

Animals were killed using $\mathrm{CO}_{2}$. Mice were transcardially perfused with $50 \mathrm{ml}$ of PBS, $\mathrm{pH} 7.4$, for $5 \mathrm{~min}$ followed by $100 \mathrm{ml}$ of $4 \%$ paraformaldehyde (PFA) for $10 \mathrm{~min}$. Brains were postfixed in $4 \%$ PFA for $12 \mathrm{~h}$ at $4^{\circ} \mathrm{C}$ and were subsequently transferred to a $30 \%$ sucrose solution. Forty micrometers and $100-\mu \mathrm{m}$-thick coronal brain sections were produced using a sliding microtome (Leica Microsystems) for phenotyping and morphological analysis of retrovirally manipulated cells, respectively.

\section{Histology and counting procedures}

Free-floating sections were collected in $0.1 \mathrm{~m}$ phosphate buffer and rinsed three times in TBS. Sections were blocked in TBS supplemented with 3\% donkey serum and $0.25 \%$ Triton $\mathrm{X}-100$ for $2 \mathrm{~h}$, and were incubated with primary antibodies dissolved in blocking solution at $4^{\circ} \mathrm{C}$ for $48 \mathrm{~h}$. Primary antibodies against the following antigens were used: doublecortin (DCX; goat; 1:250; Santa Cruz Biotechnology), calbindin (rabbit; 1:1000; Swant), GFP (chicken; 1:1000; Aves Labs), and RFP (rat; 1:50; a gift from Dr. Heinrich Leonhardt, Ludwig Maximilian University of Munich, $\mathrm{Mu}-$ nich, Germany).

After washing three times in TBS (each $15 \mathrm{~min}$ ) and blocking for 30 min, sections were incubated in blocking solution containing secondary antibodies conjugated to FITC, Alexa Fluor 488, Cy3, Cy5, or CF633 (Jackson Laboratory) for $2 \mathrm{~h}$. Sections were rinsed again three times in TBS, one wash step containing $(10 \mathrm{mg} / \mathrm{ml} \mathrm{4}$, 6 -diamidino-2-phenylindole; 1:10,000; Sigma-Aldrich). Sections were mounted using SuperFrost microscope slides (Menzel-Gläser) and Aqua/PolyMount (Polysciences Inc.), and were stored at $4^{\circ} \mathrm{C}$.

To phenotype genetically manipulated cells, the expression of stagespecific markers (DCX, calbindin, $n>50$ cells/per animal and marker) in newborn neurons was analyzed by confocal microscopy in at least four sections containing the dentate gyri from four to six different animals. Confocal single-plane images and $z$-stacks were obtained on a Leica $\mathrm{Mi}$ crosystems SP5 confocal microscope.

To evaluate the influence of dnDrpl on the survival of newborn cells, a previously established double-transduction protocol was applied (Tashiro et al., 2006b; Jessberger et al., 2008; Jagasia et al., 2009): survival was estimated by comparing the ratio of dnDrp1-transduced cells (mitoGFP-positive cells + mitoGFP/RFP double-positive cells) and control retrovirus-transduced cells (RFP-only-positive cells) at two different time points [ 8 and $16 \mathrm{~d}$ postinjection (dpi)].

\section{Morphology analyses}

Dendritic maximum extension index. The dendritic maximum extension index is defined as the distance between soma and the furthest reaching dendritic tip in the molecular layer divided by the distance between the soma and the hippocampal fissure, which constitutes the maximum possible extension of the dendritic tree in the dorsoventral axis (Krzisch et al., 2013). Confocal images of retrovirally labeled cells were obtained with a $40 \times$ oil objective using a TCS Sp5 confocal microscope (Leica Microsystems; step size, $0.7 \mu \mathrm{m}$; resolution, $1024 \times 1024)$. At least 50 double-transduced cells per animal from at least three different animals were analyzed, and the cumulative distribution of the dendritic maximum extension index was compared.

Evaluation of dendritic morphology. To analyze detailed dendrite morphology, confocal images of double-transduced cells were obtained with a $63 \times$ glycerol objective using a TCS Sp 5 confocal microscope (Leica Microsystems; step size, $0.3 \mu \mathrm{m}$; resolution, $1024 \times 1024)$. One hundred-micrometer-thick sections from comparable hippocampal positions were used to avoid differences due to truncated cells and different positioning, respectively. Twelve cells per group from at least three different animals were analyzed. 3D reconstructions were obtained by using the Filament Tracer tool in Imaris (Bitplane AG), and values for total dendritic length, number of branch points, and number of Sholl intersections were compared.

Spine analysis. To analyze morphological synaptic integration of transduced cells, confocal images of at least 10 dendrites in the mid-third of the molecular layer from 10 different double-transduced cells were obtained with a $63 \times$ glycerol objective (step size system optimized; resolution, $1024 \times 1024 ; 5 \times$ zoom). The length of the dendrites was measured using LAS AF software, and the number of dendritic spines was quantified. Spine number was normalized to dendritic length and compared. To analyze the maturation of spines, the number of mushroom spines (spine head, $>0.6 \mu \mathrm{m}$ ) was quantified and the percentage of the total number of spines was calculated.

Analysis of mitochondrial volume, number, and distribution. Mitochondria volumes were analyzed by the reconstruction of mitochondria using the Surface tool of the Imaris Software (Bitplane AG) in the same confocal images that were used for the morphology analyses. Mitochondria number and volume were reconstructed from mitochondria-targeted fluorescence.

Dendritic mitochondria distribution was analyzed by dividing the dendritic tree of $3 \mathrm{D}$ reconstructed cells into the proximal dendritic tree 
(i.e., dendritic segments within a $100 \mu \mathrm{m}$ radius from soma, excluding the dendritic shaft) and the distal dendritic tree (i.e., dendritic segments above a $100 \mu \mathrm{m}$ radius from soma). Mitochondria volume and number were individually calculated per section.

\section{Statistical analysis}

Significance levels for global morphology analysis were assessed by twoway ANOVA. For all other data, the unpaired Student's $t$ test with unequal variances was used. Differences were considered statistically significant at ${ }^{*} p<0.05,{ }^{* *} p<0.01$, and ${ }^{* * *} p<0.001$. All data are presented as the mean \pm SEM.

\section{Results}

In vivo development of adult-born hippocampal neurons is paralleled by changes in mitochondrial morphology and distribution

To visualize mitochondria and cell morphology in adult-born neurons, MML retrovirus encoding for mitochondriatargeted GFP (CAG-IRES mitoGFP) was generated and coinjected with an MML retrovirus encoding for RFP (CAG-RFP) into the DGs of young adult mice. Animals were killed at different time intervals after retroviral injection (dpi) for morphological analysis of newborn neurons at different developmental stages.

In line with previous reports (Zhao et al., 2006; Sun et al., 2013), extensive dendritic growth occurred between the second and fourth week of neuronal development (Fig. 1). Between 16 and $28 \mathrm{dpi}$, total dendritic length increased by approximately threefold from $395 \pm 17 \mu \mathrm{m}$ ( $16 \mathrm{dpi}$ ) to $1174 \pm 45 \mu \mathrm{m}$ ( $28 \mathrm{dpi}$ ). The dendritic morphology of 28 dpi neurons closely resembled the morphology of neurons at later time points (up to $106 \mathrm{dpi}$ ), and there was only very modest dendrite growth after $28 \mathrm{dpi}$ (total dendritic length at $106 \mathrm{dpi}, 1309 \pm 61 \mu \mathrm{m}$ ).

The development of new neurons was accompanied by changes in mitochondrial morphology and distribution, and increases in mitochondrial mass (Fig. 1). At early time points (3 and $7 \mathrm{dpi}$ ), mitochondria were mostly located in the soma and in the initial segment of processes, where they formed large tubular structures (Fig. 1B). At later time points (16-42 dpi), mitochondria in the soma and the dendritic shaft became increasingly fragmented, and were of mixed tubular and globular shape (Fig. 1B); these developmental stages were in addition characterized by the presence of round-shaped mitochondria in the dendritic arbor (Fig. 1C). At $106 \mathrm{dpi}$, mitochondria in the soma were in most cases of mixed tubular and globular shapes but occasionally formed a prominent interconnected network, which extended into the dendritic shaft (Fig. $1 B$ ); similar to earlier time points, dendritic mitochondria were mostly of round morphology (Fig. 1C).

The extensive dendritic growth between 16 and 28 dpi was accompanied by a massive increase in total mitochondrial volume (16 dpi, $80 \pm 8 \mu \mathrm{m}^{3}$; $28 \mathrm{dpi}, 204 \pm 15 \mu \mathrm{m}^{3}$ ); mitochondrial volume was further increased at $106 \mathrm{dpi}\left(353 \pm 27 \mu \mathrm{m}^{3}\right)$. Mitochondrial content in the soma and the dendritic shaft was comparable between $16 \mathrm{dpi}\left(63 \pm 7 \mu \mathrm{m}^{3}\right)$ and $28 \mathrm{dpi}\left(55 \pm 4 \mu \mathrm{m}^{3}\right)$, and was only modestly increased at $106 \mathrm{dpi}\left(85 \pm 6 \mu \mathrm{m}^{3}\right)$. The increase in total mitochondrial content was mostly owing to a continuous increase in mitochondria localized to the dendritic arbor (16 dpi, $17 \pm 3 \mu \mathrm{m}^{3} ; 28 \mathrm{dpi}, 149 \pm 13 \mu \mathrm{m}^{3}$; $106 \mathrm{dpi}, 270 \pm$ $13 \mu \mathrm{m}^{3}$; Fig. $1 C$ ). Dendritic mitochondrial content indices (i.e., mitochondrial volume normalized to total dendritic length excluding the dendritic shaft) continuously increased between 16 and $106 \mathrm{dpi}\left(16 \mathrm{dpi}, 0.05 \pm 0.01 \mu \mathrm{m}^{3} / \mu \mathrm{m} ; 28 \mathrm{dpi}, 0.14 \pm 0.01\right.$ $\left.\mu \mathrm{m}^{3} / \mu \mathrm{m} ; 106 \mathrm{dpi}, 0.23 \pm 0.02 \mu \mathrm{m}^{3} / \mu \mathrm{m}\right)$, demonstrating that

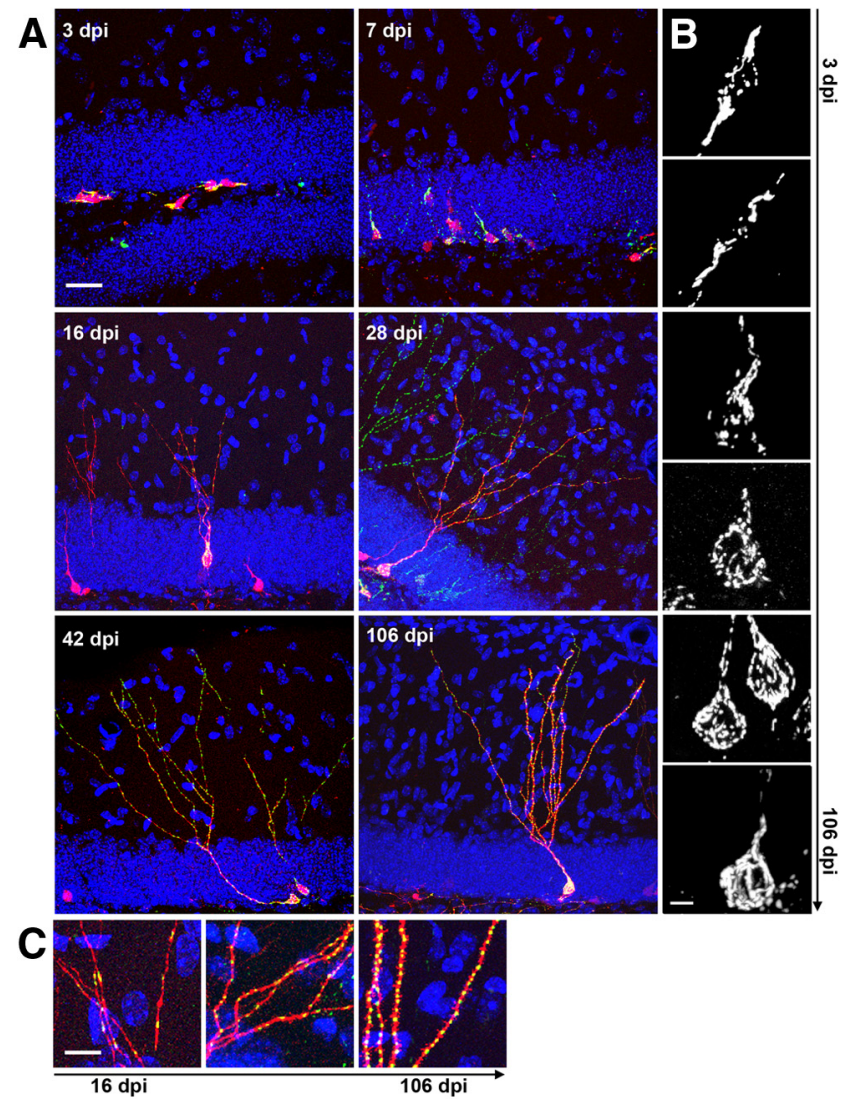

Figure 1. Mitochondrial morphology and localization during the development of adultgenerated DG neurons. $A$, Development of adult-born neurons (red) is paralleled by increase in mitochondria mass (mitochondria in green). Scale bar, $25 \mu \mathrm{m}$. $\boldsymbol{B}$, Higher magnification reveals distinct morphologies of somatic mitochondria. At early stages, mitochondria predominantly formed large tubular structures. Between 16 and $42 \mathrm{dpi}$, mitochondria were of a mixed tubular and globular shape. At $106 \mathrm{dpi}$, mitochondria in some adult-generated neurons formed an interconnected network. Note the dense packing of the dendritic shaft with mitochondria at al developmental time points. Scale bar, $3 \mu \mathrm{m}$. C, Higher magnification of the dendritic mitochondria at 16,28 , and 106 dpi reveals an increasing presence of round mitochondria. Scale bar, 8 $\mu \mathrm{m}$.

there was no simple linear relationship between dendritic mitochondrial content and the size of the dendritic arbor. At each time point, the dendritic mitochondrial content indices in proximal dendritic segments $(<100 \mu \mathrm{m}$ distance from soma, excluding the dendritic shaft, which showed a high density of mitochondria) and distal dendritic segments $(>100 \mu \mathrm{m}$ distance from soma) were comparable (Table 1), indicating that mitochondria were efficiently distributed throughout the dendritic arbor.

In summary, the development of new DG neurons is paralleled by extensive mitochondrial biogenesis, which continues beyond the period of extensive dendritic growth. The most profound changes in mitochondrial morphology and distribution were observed around the second week, and coincided with the time of rapid dendritic growth activity and the initiation of spine development (Zhao et al., 2006; Sun et al., 2013). This period was characterized by a change in the morphology of soma and dendritic shaft mitochondria from large tubular structures to a mixed tubular and globular shape, and by the appearance of round-shaped mitochondria in the dendritic arbor. Collectively, these observations strongly suggest that remodeling of the mitochondrial compartment is part of a coordinated in vivo neuronal developmental program. 
Table 1. Comparison of the parameters mitochondrial volume and mitochondrial density in 16 and 28 dpi neurons between control mice and mice with access to running wheels

\begin{tabular}{|c|c|c|c|c|c|c|}
\hline & Control $16 \mathrm{dpi}$ & Runner $16 \mathrm{dpi}$ & $p$ value & Control $28 \mathrm{dpi}$ & Runner $28 \mathrm{dpi}$ & $p$ value \\
\hline \multicolumn{7}{|l|}{ Absolute mitochondrial volume $\left(\mu \mathrm{m}^{3}\right)$} \\
\hline Whole cell & $80 \pm 8$ & $286 \pm 39$ & $<0.001$ & & & \\
\hline Soma + dendritic shaft & $63 \pm 7$ & $150 \pm 16$ & $<0.001$ & & & \\
\hline Dendritic tree & $17 \pm 3$ & $136 \pm 26$ & $<0.001$ & & & \\
\hline Proximal dendrites $(<100 \mu \mathrm{m})$ & $15 \pm 2$ & $70 \pm 9$ & $<0.001$ & & & \\
\hline Distal dendrites (>100 $\mu \mathrm{m})$ & $1 \pm 0.8$ & $66 \pm 18$ & $<0.01$ & & & \\
\hline \multicolumn{7}{|c|}{ Mitochondrial density index ( $\mu \mathrm{m}^{3} / \mu \mathrm{m}$ length) } \\
\hline Whole cell & $0.20 \pm 0.02$ & $0.30 \pm 0.04$ & 0.05 & & & \\
\hline Soma + dendritic shaft & $0.75 \pm 0.09$ & $1.54 \pm 0.23$ & $<0.01$ & & & \\
\hline Dendritic tree & $0.05 \pm 0.006$ & $0.15 \pm 0.03$ & $<0.01$ & & & \\
\hline Proximal dendrites $(<100 \mu \mathrm{m})$ & $0.06 \pm 0.006$ & $0.18 \pm 0.03$ & $<0.01$ & & & \\
\hline Distal dendrites (>100 $\mu \mathrm{m})$ & $0.07 \pm 0.05$ & $0.13 \pm 0.03$ & 0.3 & & & \\
\hline \multicolumn{7}{|l|}{ Absolute mitochondrial volume $\left(\mu \mathrm{m}^{3}\right)$} \\
\hline Whole cell & & & & $204 \pm 15$ & $253 \pm 23$ & 0.09 \\
\hline Soma + dendritic shaft & & & & $55 \pm 4$ & $66 \pm 9$ & 0.29 \\
\hline Dendritic tree & & & & $149 \pm 13$ & $187 \pm 17$ & 0.1 \\
\hline Proximal dendrites $(<100 \mu \mathrm{m})$ & & & & $44 \pm 4$ & $50 \pm 5$ & 0.38 \\
\hline Distal dendrites (>100 $\mu \mathrm{m})$ & & & & $105 \pm 10$ & $137 \pm 13$ & 0.07 \\
\hline \multicolumn{7}{|c|}{ Mitochondrial density index ( $\mu \mathrm{m}^{3} / \mu \mathrm{m}$ length) } \\
\hline Whole cell & & & & $0.17 \pm 0.01$ & $0.20 \pm 0.02$ & 0.14 \\
\hline Soma + dendritic shaft & & & & $0.60 \pm 0.05$ & $0.78 \pm 0.07$ & 0.06 \\
\hline Dendritic tree & & & & $0.14 \pm 0.01$ & $0.16 \pm 0.02$ & 0.20 \\
\hline Proximal dendrites $(<100 \mu \mathrm{m})$ & & & & $0.13 \pm 0.01$ & $0.17 \pm 0.02$ & 0.11 \\
\hline Distal dendrites (>100 $\mu \mathrm{m})$ & & & & $0.14 \pm 0.01$ & $0.16 \pm 0.02$ & 0.26 \\
\hline
\end{tabular}

Data is given as mean $\pm \mathrm{SEM}$.

\section{Voluntary exercise-induced acceleration of morphological maturation is paralleled by remodeling of the mitochondrial compartment}

Next, neuronal morphology and mitochondria of retrovirally birthdated DG neurons were studied in the context of voluntary wheel running - a behavioral stimulus that potently stimulates neurogenesis (van Praag et al., 1999) and promotes the maturation of adult-born DG neurons as evidenced by the accelerated formation of spines and the expression of mature neuronal markers (Zhao et al., 2006; Piatti et al., 2011). First, we analyzed dendritic development - an aspect of maturation that had not been systematically assessed in the context of voluntary exercise thus far. Analysis at 16 dpi revealed that voluntary exercise strongly promoted maturation, as reflected by a more than twofold increase in total dendritic length (exercise group, $857 \pm 45 \mu \mathrm{m}$; control group, $395 \pm 17 \mu \mathrm{m} ; p<0.001$ ), an increased number of dendritic branch points (exercise group, $14 \pm 1$; control group, $11 \pm 1 ; p<0.05$ ), enhanced dendritic complexity (Fig. $2 A-D$ ), and a higher maximum dendrite extension index (data not shown).

Newborn neurons in the exercise group contained more mitochondria (Table 1). Most notably, the mitochondrial content in the soma and dendritic shaft region was increased $\sim 2.5$-fold (control group, $63 \pm 7 \mu \mathrm{m}^{3}$; runner group, $150 \pm 16 \mu \mathrm{m}^{3}$ ) and exceeded by far the soma/dendritic shaft mitochondrial content in older neurons (28 dpi), even if these had developed in the context of running (see below; Table 1). The mitochondrial content indices for the entire dendritic arbor, for proximal dendritic segments, and for distal dendritic segments were comparable within the exercise group, indicating that the increased mitochondrial mass was evenly and efficiently distributed throughout the dendritic arbor (Table 1). While the dendritic shaft of neurons was densely packed with tubular mitochondria in all $16 \mathrm{dpi}$ neurons, mitochondria in this compartment tended to be less tubular and more globular shaped in neurons of the runner group (Fig. 2E).

We also examined whether continuous voluntary exercise would affect dendrite morphology and mitochondria at later stages. Dendrite morphology of 28 dpi neurons in the exercise group was highly similar to the morphology of neurons in the control group (Fig. 2E-H). In accordance with previous reports (Zhao et al., 2006; Piatti et al., 2011), voluntary exercise did not induce differences in spine density and number of mushroom spines at this developmental time point (data not shown). No significant differences were detected in total mitochondrial volume (Table 1). In both conditions, mitochondria in the soma and dendritic shaft region were of a mixed globular and tubular shape with a predominance of globular-shaped mitochondria (Fig. 2E). The only significant differences were small increases in the number of dendritic mitochondria (control group, 0.24 mitochondria/ $\mu \mathrm{m}$ dendrite; runner group, 0.32 mitochondria/ $\mu \mathrm{m}$ dendrite; $p<0.001$ ) but not in mitochondrial volume or density indices in dendritic segments in the runner group (Table 1), suggesting that voluntary exercise slightly promoted mitochondrial fission.

Collectively, these data demonstrate that voluntary exercise accelerates dendrite development but does not permanently alter dendrite morphology, thereby supporting the notion that voluntary exercise enhances the tempo of maturation of adultgenerated neurons (Zhao et al., 2006; Piatti et al., 2011). The data also strongly suggest an exquisite sensitivity of immature adultgenerated neurons to the voluntary exercise stimulus during the period of rapid dendritic growth. Intriguingly, exercise-induced dendritic development in immature neurons was paralleled by increased mitochondrial content, increased presence of globular mitochondria in the dendritic shaft, and enhanced distribution of mitochondria to the dendritic arbor, indicating that exercise ac- 
A

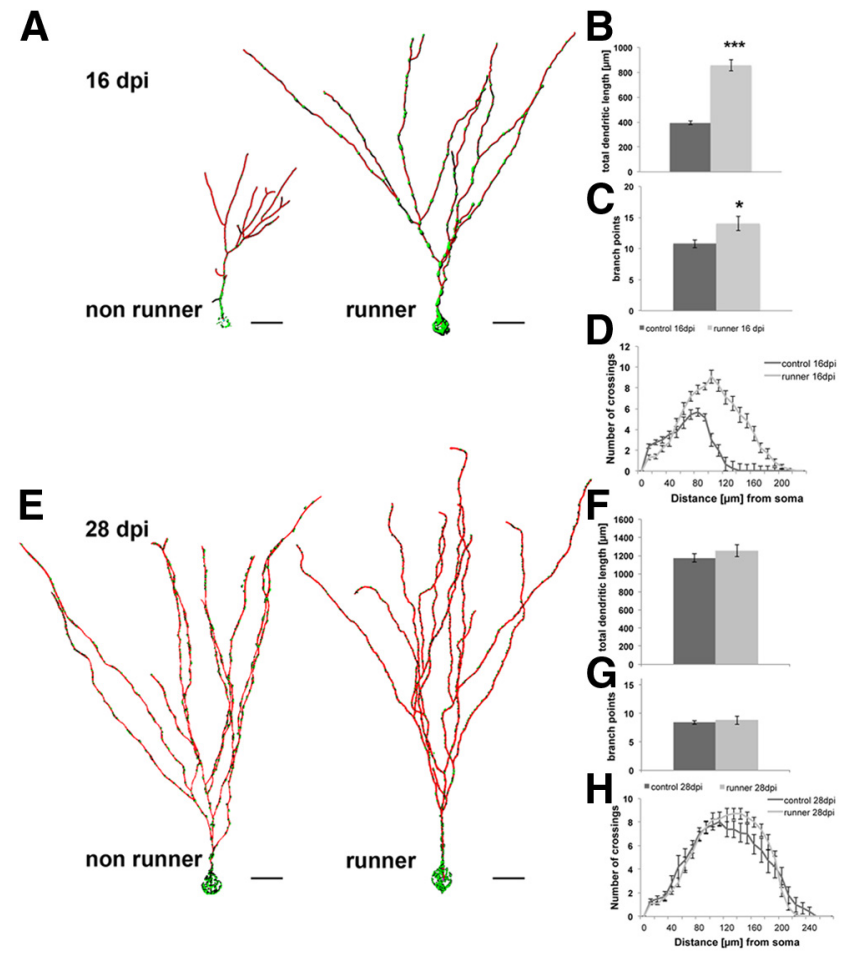

Figure 2. Running accelerates dendritic development and transiently increases mitochondrial mass and dendritic mitochondrial content. $\boldsymbol{A}$, Reconstruction of 16 dpi neurons in mice housed under control conditions (nonrunners) and mice with access to running wheels. Mitochondria in green, dendrites in red. Scale bar, $20 \mu \mathrm{m} . \boldsymbol{B}-\boldsymbol{D}$, Comparison of the dendritic parameters total dendritic length $(\boldsymbol{B})$, branch points $(\boldsymbol{C})$, and Sholl analysis $(\boldsymbol{D})$ in 16 dpi neurons between mice housed under control conditions (control $16 \mathrm{dpi}$ ) and mice with access to running wheels (runner $16 \mathrm{dpi)}$. $\boldsymbol{E}$, Reconstruction of $28 \mathrm{dpi}$ neurons in mice housed under control conditions (nonrunners) and mice with access to running wheels. Mitochondria, Green; dendrites, red. Scale bar, $20 \mu \mathrm{m}$. $\boldsymbol{F}-\boldsymbol{H}$, Comparison of the dendritic parameters total dendritic length $(\boldsymbol{F})$, branch points $(\boldsymbol{G})$, and Sholl analysis $(\boldsymbol{H})$ in 28 dpi neurons between mice housed under control conditions (control $28 \mathrm{dpi}$ ) and mice with access to running wheels (runner 28 dpi). Data are given as the mean \pm SEM. Error bars represent the SEM.

celerated maturation at least in part through the modulation of mitochondrial biogenesis, morphology, and distribution.

\section{Mitochondrial dynamics and distribution modifies} differentiation and maturation in adult neurogenesis We also sought to determine whether alterations to mitochondrial morphology and dendritic distribution alter the development of new DG neurons. To this end, we genetically manipulated the activity of the GTPase Drp1, which controls mitochondrial morphology and facilitates mitochondrial distribution by promoting mitochondrial fission (Yaffe, 1999; Misaka et al., 2002).

The effects of enhanced Drp1 activity on the development of new DG neurons were first examined in mice that were housed under standard conditions. Analysis was performed $16 \mathrm{~d}$ after injection of a retrovirus, which bicistronically encoded for Drp1 and a mitochondria-targeted fluorescent marker, or of a control retrovirus. A second retrovirus encoding for ubiquitously expressed fluorescent protein was coinjected to visualize the overall morphology of the newborn neuron. Mitochondrial content in 16 dpi neurons was comparable between the two experimental groups (control group, $80 \pm 8 \mu \mathrm{m}^{3}$; Drp1 group, $82 \pm 10 \mu \mathrm{m}^{3}$ ). Consistent with previous reports (Li et al., 2004), the overexpression of Drp1 was sufficient to increase mitochondrial fission and dendritic distribution, as evidenced by the increased presence of
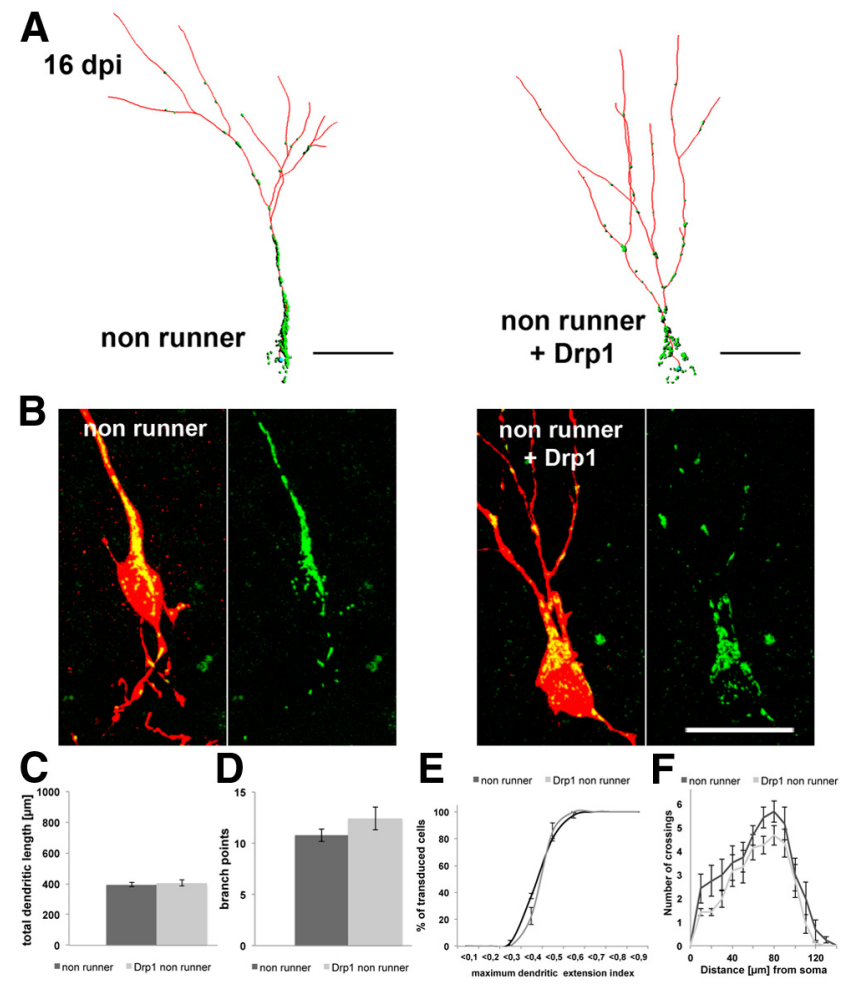

Figure 3. Drp1 overexpression does not alter dendrite morphology of newborn neurons in nonrunning animals. $\boldsymbol{A}$, Reconstruction of $16 \mathrm{dpi}$ neurons in mice housed under control conditions. Control neuron is shown on the left (nonrunner), Drp1-transduced neuron is shown on the right. Mitochondria, green; dendrites, red. Scale bar, $20 \mu \mathrm{m}$. $\boldsymbol{B}$, Higher magnification of mitochondria (green) in the soma and dendritic shaft of control and Drp1 retrovirus-transduced cells (red). Note the increased presence of fragmented mitochondria in Drp1-transduced cells. Scale bar, $20 \mu \mathrm{m}$. $\boldsymbol{C}-\boldsymbol{F}$, Comparison of the dendritic parameters total dendritic length $(\boldsymbol{C})$, branch points $(\boldsymbol{D})$, maximum extension index $(\boldsymbol{E})$, and Sholl analysis $(\boldsymbol{F})$ in control and Drp1overexpressing $16 \mathrm{dpi}$ neurons. Data are given as the mean $\pm \mathrm{SEM}$. Error bars represent the SEM.

globular mitochondria in the dendritic shaft and the increased density of dendritic mitochondria with a round morphology (Fig. $3 A, B$ ). Drp1-expressing and control neurons did not differ with regard to dendritic length, number of branch points, the maximum dendritic extension index, and dendritic complexity (Fig. 3C-F). In line with previous observations that neurons initiate spinogenesis at $16 \mathrm{~d}$ of age (Zhao et al., 2006), dendrites of neurons in both experimental groups only occasionally bore spines. Thus, Drp1 overexpression and the resulting enhancement of mitochondrial fission and increase in dendritic mitochondrial content were not sufficient to promote in vivo dendritic development.

Next, we examined the effects of Drp1 overexpression under voluntary exercise conditions. At $16 \mathrm{dpi}$, mitochondria in the soma and the dendritic shaft were of mixed tubular and globular morphology in control neurons but were predominantly of globular morphology in Drp1-overexpressing neurons (Fig. $4 A, B$ ). Drp1-overexpressing neurons tended to have lower mitochondrial content in the soma and dendritic shaft (control group,

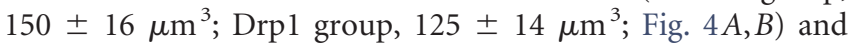
contained higher numbers of mitochondria in their dendrites (control group, $0.16 \pm 0.02$ mitochondria/ $\mu \mathrm{m}$; Drp1 group, $0.22 \pm 0.01$ mitochondria/ $\mu \mathrm{m} ; p<0.001$; Fig. $4 I$ ), indicating that Drp1 overexpression resulted in the distribution of mitochondria from the soma and dendritic shaft to the dendritic arbor. Total dendritic length was similar between the two 


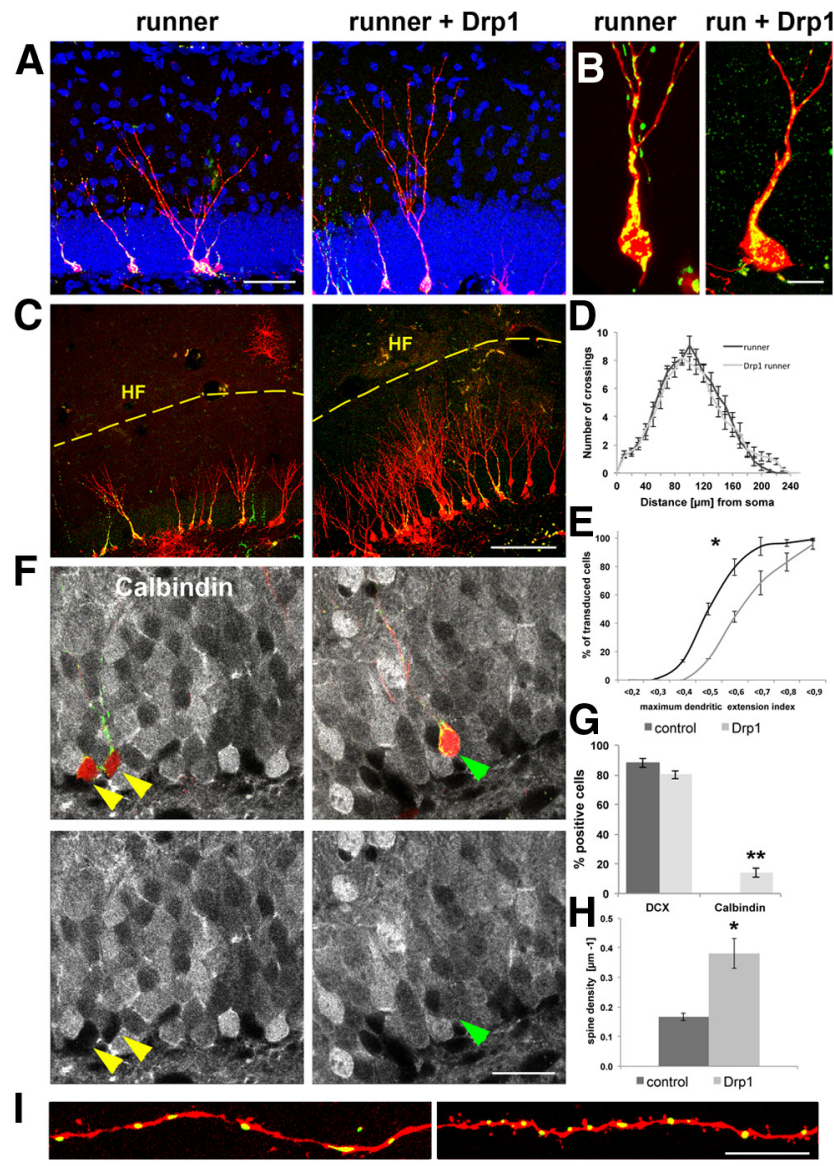

Figure 4. Drp1 overexpression accelerates running-induced maturation. $A$, Overexpression of Drp1 promotes dendritic growth in 16 dpi neurons in the context of running. Control neurons are shown on the left (runner), and Drp1-overexpressing neurons in the running condition are shown on the right (runner + Drp1). Drp1-overexpressing neurons are identified by coexpression of mitochondria-targeted fluorescent protein (green). DAPI, Blue. Scale bar, $25 \mu \mathrm{m}$. $\boldsymbol{B}$, Higher magnification of mitochondria (green) in control and Drp1 retrovirus-transduced cells (red). Note the increased presence of globular-shaped mitochondria, the reduction in mitochondria in the soma and dendritic shaft, and the globular shape of mitochondria in the dendritic arbor of Drp1-transduced cells. Scale bar, $10 \mu \mathrm{m}$. C, Drp1-overexpressing neurons show enhanced dendritic extension toward the hippocampal fissure. Drp1-overexpressing neurons are identified by coexpression of mitochondria-targeted fluorescent protein (green). Scale bar, $100 \mu \mathrm{m} . \boldsymbol{D}, \boldsymbol{E}$, Sholl analysis plot $(\boldsymbol{D})$ and comparative cumulative distribution plot $(\boldsymbol{E})$ of the maximum dendrite extension index of 16 dpi neurons in running only conditions (control) and running + Drp1 overepxression conditions (Drp1). ${ }^{*} p<0.05 . F$, The 16 dpi neurons (in red) in running-only conditions are negative for the mature neuronal marker calbindin (gray, yellow arrowheads). A significant fraction of Drp1-overexpressing neurons express calbindin (green arrowheads). Mitochondria, Green. Scale bar, $15 \mu \mathrm{m}$. G, Quantification of expression of the immature neuronal marker $D C X$ and calbindin in 16 dpi neurons. $\boldsymbol{H}, \boldsymbol{I}$, Drp1 overepression increases spine density in $16 \mathrm{dpi}$ neurons in running mice. Scale bar, $10 \mu \mathrm{m}$. Data are given as the mean \pm SEM. Error bars represent the SEM.

experimental groups (control group, $857 \pm 45 \mu \mathrm{m}$; Drp1 group, $875 \pm 53 \mu \mathrm{m})$. The dendritic arbor of Drp1-overexpressing neurons, however, frequently appeared more elaborate (Fig. $4 A$ ), and the analysis of the number of branching points (control group, $14 \pm 1$; Drp1 group, $17 \pm 2$ ) showed a trend toward higher dendritic complexity in Drp1-overexpressing neurons. Moreover, we observed in the Sholl analysis that Drp1-overexpressing neurons tended to have higher numbers of dendritic intersections at distances of $>200 \mu \mathrm{m}$ from the cell body (Fig. 4D), which suggested that Drp1-overexpressing neurons bore a dendritic tree that reached closer to the hippocampal fissure. Indeed, the maximum extension index of Drp1-overexpressing neurons was significantly increased ( $p<0.05$; Fig. $4 C, E)$.
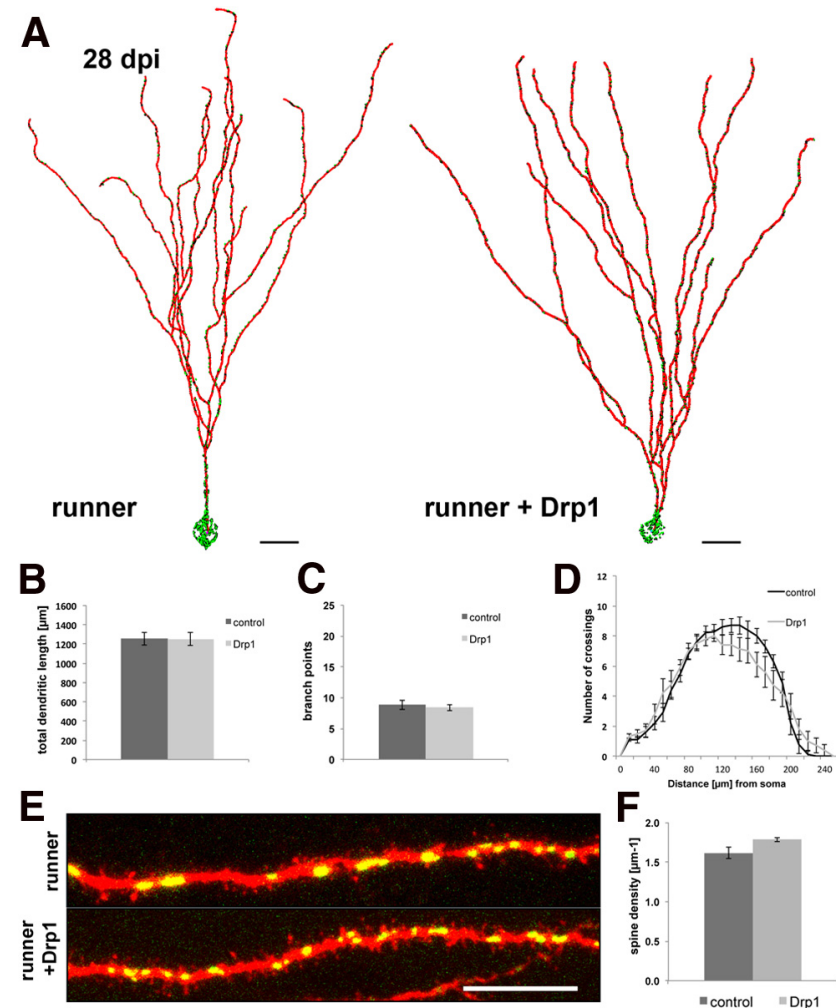

Figure 5. Drp1 overexpression does not permanently alter dendrite morphology and spine density. $A$, Reconstruction of 28 dpi neurons in mice with access to running wheels in the absence (runner) and presence (runner + Drp1) of Drp1 overexpression. Mitochondria, Green; dendrites, red. Scale bar, $20 \mu \mathrm{m}$. $\boldsymbol{B}-\boldsymbol{D}$, Comparison of the dendritic parameters total dendritic length $(\boldsymbol{B})$, branch points $(\boldsymbol{C})$, and Sholl analysis $(\boldsymbol{D})$ in 28 dpi neurons between mice with access to running wheels in the absence (control) and presence (Drp1) of Drp1 overexpression. $\boldsymbol{E}, \boldsymbol{F}$, Comparison of spinogenesis in $28 \mathrm{dpi}$ neurons between mice with access to running wheels in the absence (control) and presence (Drp1) of Drp1 overexpression. E, Mitochondria, Green. Scale bar, $10 \mu \mathrm{m}$. Data are given as the mean \pm SEM. Error bars represent the SEM.

A significant fraction of Drp1-overexpressing neurons had initiated the expression of the mature dentate granule cell marker calbindin (control group, 0\%; Drp1 group, $14 \pm 3 \%$; $p<0.01$; Fig. $4 G, F)$. Most intriguingly, Drp1-overexpressing neurons displayed increased spine formation, as reflected by the higher spine density (Fig. 4H,I); almost all spines in both experimental conditions were thin spines (i.e., spines with small spine heads and thin necks). These data demonstrate that Drp1 overexpression enhanced neuronal maturation in the context of exercise.

We also examined the morphological phenotype of Drp1overexpressing neurons at $28 \mathrm{dpi}$ in the context of voluntary running. No significant differences of absolute mitochondrial volume, relative mitochondrial volume normalized to cell size, localization of mitochondria within the cells, and mitochondrial density were found between the experimental groups (data not shown). In both groups, mitochondria in the soma and the dendritic shaft were predominantly of globular morphology. In contrast to the differences observed at $16 \mathrm{dpi}$, Drp1-transduced cells at 28 dpi were indistinguishable from control cells with regard to dendritic parameters (Fig. $5 A-D$ ) and spine-related parameters (spine density: control group, $1.61 \pm 0.07$ spines $/ \mu \mathrm{m}$; Drp1 group, $1.78 \pm 0.02$ spines $/ \mu \mathrm{m}$; fraction of mushroom spines: control group, $5 \pm 1 \%$; Drp1 group, $5 \pm 1 \%$; Fig. $5 E, F$ ). Thus, Drp1 overexpression combined with voluntary exercise caused acceleration of dendritic growth and spine formation rather than permanent gain in dendritic complexity and spine density. 


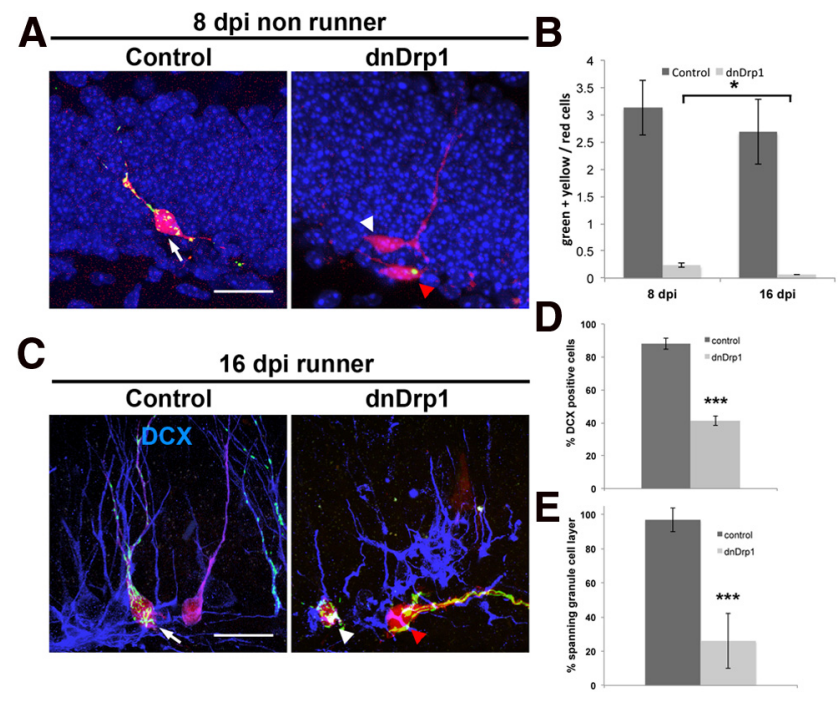

Figure 6. Effects of dnDrp1 expression on neurogenesis under basal conditions and in the context of voluntary exercise. $\boldsymbol{A}$, Under basal conditions, control transduced 8 dpi neurons show polarized morphology and start to grow a primary dendrite toward the molecular cell layer (white arrow). dnDrp1-expressing cells (red arrowhead) showed stunted morphology and limited mitochondrial content (in green). Cells in the same animal, which were transduced only with the control RFP-encoding retrovirus (white arrowhead), grow a primary dendrite toward the molecular cell layer. Scale bar, $15 \mu \mathrm{m}$. B, Comparison of the ratio between all mitoGFPpositive cells (green + yellow) to RFP-only cells (red) under nonrunning conditions. Note that the ratio decreases between 8 and $16 \mathrm{dpi}$ in dnDrp1 retrovirus-injected animals. C, Running conditions: control-transduced 16 dpi neurons express the immature neuronal marker DCX (in blue; white arrow). dnDrp1-expressing cells frequently fail to express DCX and extend processes parallel to the subgranular zone (red arrowhead). Note the long tubular mitochondrial morphology. dnDrp1-expressing cells, which are positive for $D C X$, only grow short dendrites toward the molecular cell layer (white arrowhead). Note that mitochondria are confined to the soma. Scale bar, $15 \mu \mathrm{m}$. D, Quantification of transduced cells expressing DCX at 16 dpi under running conditions. $\boldsymbol{E}$, Quantification of transduced cells bearing a primary dendrite spanning the granule cell layer at $16 \mathrm{dpi}$ under running conditions. Error bars represent the SEM.

Next, we examined the consequences of inhibition of mitochondrial fission and distribution on the development of adult-generated DG neurons. The dnDrp1 mutant inhibits Drp1-dependent fission and distribution, and causes perinuclear accumulation of mitochondria (Smirnova et al., 2001; Li et al., 2004). First, we examined the effects of dnDrp1 on basal neurogenesis. Analysis was performed 8 or $16 \mathrm{~d}$ after injection of a retrovirus, which bicistronically encoded for dnDrp1 and mitochondria-targeted GFP combined with a second retrovirus encoding for RFP to visualize the overall morphology of the newborn neuron. Control animals were injected with a combination of mitochondria-targeted GFP retrovirus and RFP retrovirus. mitoGFP-expressing cells were abundant in control animals; despite the injection of retroviruses of comparable titer, dnDrp1/ mitoGFP-transduced cells were only occasionally observed at 8 dpi and were almost completely absent at $16 \mathrm{dpi}$, which precluded further analysis of the impact of $\operatorname{dnDrp} 1$ on fate choice and maturation of newborn neurons. The few remaining dnDrp1/mitoGFP-transduced cells at $8 \mathrm{dpi}$ appeared to fail to extend a primary dendrite toward the granule cell layer and contained very few mitochondria (Fig. 6A), the latter phenotype potentially reflecting the crucial function of fission in mitochondrial biogenesis (Attardi and Schatz, 1988; Osman et al., 2011). The ratio between all mitoGFP-positive cells to RFP-only cells was stable in control mice between time points $(3.13 \pm 0.51$ vs $2.69 \pm 0.59$ at 8 and $16 \mathrm{dpi}$, respectively); in contrast, the ratio of dnDrp1 cells (all mitoGFP-positive cells) to control retrovirus- transduced cells (RFP-only cells) dropped between time points $(0.20 \pm 0.03$ vs $0.06 \pm 0.003 ; p<0.05$; Fig. $6 B)$, strongly indicating that the inhibition of Drp1 massively impaired the survival of newborn cells.

Finally, the consequences of $\mathrm{dnDrp} 1$ on voluntary exerciseinduced development of adult-generated DG neurons were examined. Surprisingly and in contrast to basal conditions, cells transduced with dnDrp1-encoding virus were present in mice exercising voluntarily at $16 \mathrm{dpi}$. According to the notion that dnDrpl inhibits fission and distribution, and causes perinuclear accumulation of mitochondria (Smirnova et al., 2001; Li et al., 2004), dnDrp1 expression resulted in a profound alteration in mitochondrial shape and distribution: mitochondria in cells with a non-neuronal morphology (see below) displayed a highly tubular shape and reached a maximum length of $43 \mu \mathrm{m}$. In contrast, the longest mitochondrion in control neurons was $\sim 5 \mu \mathrm{m}$ (Fig. $6 C$ ). In dnDrp1 cells with neuronal morphology (see below), the total mitochondrial volume was reduced to $74 \pm 7 \mu \mathrm{m}^{3}$ (total mitochondrial volume in control cells, $286 \pm 39 \mu \mathrm{m}^{3}$ ) with almost all mitochondria located in the soma (Fig. $6 C$ ), again underlining the crucial function of fission in mitochondrial biogenesis and distribution (Attardi and Schatz, 1988; Osman et al., 2011).

At $16 \mathrm{dpi}$, the vast majority of control cells expressed the immature neuronal marker DCX, extended a primary dendrite spanning the granule cell layer $(97 \pm 7 \%$ of control transduced cells), and grew a dendritic arbor in the molecular layer. In contrast, the majority of dnDrp1-transduced cells lacked the typical dentate granule cell morphology and grew processes parallel to the subgranular zone (Fig. 6C). Those dnDrp1-transduced cells that exhibited a neuronal morphology and bore a primary process spanning the granule cell layer $(26 \pm 16 \%$ of dnDrp 1 transduced cells; Fig. 6E), invariably displayed stunted and irregular dendritic growth with short dendrites (controls: total dendritic length, $88 \pm 23$ vs $857 \pm 45 \mu \mathrm{m} ; p<0.001)$ and almost completely abolished branching (controls: number of branch points, $1 \pm 0.4$ vs $14 \pm 1 ; p<0.001$; Fig. $6 C$ ). Consistent with the observation that dnDrp1-transduced cells frequently failed to display a neuronal morphology, the expression of the immature neuron-specific marker DCX was greatly decreased (control group, $88 \pm 3 \%$; dnDrp1 group, $41 \pm 6 \%$; $p<0.001$; Fig. $6 C, D$ ). Hence, dnDrp1 expression in mice exercising voluntarily strongly impaired dendrite growth of adult-generated neurons and interfered with neuronal differentiation of neural precursor cells.

In summary, the profound consequences of loss-of-Drp1 function for survival, neuronal differentiation, and dendritogenesis under basal and exercising conditions strongly underline the dependency of developing neurons on mitochondrial function for a broad variety of processes. Moreover, the effects of gain-ofDrp1 function on spinogenesis and the expression of mature DG neuron markers in exercising conditions indicates that the timing of maturation is particularly sensitive to mitochondrial function and regulation.

\section{Discussion}

Here, we provide for the first time evidence that mitochondria are not only required for general cell physiology in adult neurogenesis but exert modulatory function over the timing of maturation of adult-born hippocampal neurons. First, the development of adult-born neurons is paralleled by a profound gain in mitochondrial mass, by changes of mitochondrial morphology, and by increased dendritic mitochondrial content. Second, exercise-a stimulus that potently accelerates neuronal maturation 
(Zhao et al., 2006; Piatti et al., 2011)_promotes mitochondrial biogenesis and morphological remodeling of mitochondria. Third, impaired mitochondrial fission and dendritic distribution strongly decrease the survival of newly generated cells under basal conditions, and impede morphological development and the expression of neuron-specific markers during exercise-induced neurogenesis. Last and most strikingly, increasing mitochondrial fission and supporting dendritic distribution modulates the speed of voluntary exercise-induced maturation, as reflected by enhanced dendritic growth, spine formation, and the expression of mature DG markers.

In growing cells, mitochondrial membranes increase in proportion to cell mass (Attardi and Schatz, 1988). Accordingly, the continuous increase in mitochondrial mass during the development of the adult-generated neuron is, at least in part, explained by cellular growth. It is, however, of note that (1) the rate of mitochondrial biogenesis exceeds the rate of dendritic growth and (2) mitochondrial biogenesis continues past the period of extensive dendritic growth, suggesting that the maturing neuron becomes increasingly dependent on mitochondrial metabolism and homeostasis.

Mitochondria displayed distinct morphologies during different developmental stages of adult neurogenesis. The massive decrease in the number of newborn cells following dnDrp1 expression demonstrates the importance of precise regulation of mitochondrial morphology for the survival of adult-generated neurons. In addition, the profound impairment of neuronal differentiation and maturation following dnDrp1-mediated inhibition of mitochondrial fission as well as the maturationpromoting effects of Drp1 overexpression in the context of voluntary exercise underline the idea that tight regulation of mitochondrial morphology is essential for development of the postsynaptic compartment.

At present, we can only speculate on the function of differentially shaped mitochondria in the development of adultgenerated neurons. In vitro findings indicate that mitochondrial fusion and fission alter bioenergetics, which in turn influences neuronal morphogenesis (Dickey and Strack, 2011). In addition, mitochondrial morphology is related to mitochondrial biogenesis, and mitochondrial fission is crucial for efficient distribution of new mitochondria to the growing axon and dendritic tree in cultured neurons (Li et al., 2004). Mitochondria are generated via growth of pre-existing mitochondria and subsequent fission (Attardi and Schatz, 1988; Osman et al., 2011). The concentration of tubular mitochondria to the soma and the dendritic shaft, the increasing appearance of globular mitochondria in these cellular compartments during the period of extensive dendritogenesis and spinogenesis, and the round-shaped morphology of mitochondria in the dendritic arbor may reflect that mitochondrial biogenesis in developing neurons occurs in close proximity to the soma and that mitochondria are distributed from there into the growing dendritic arbor.

Previous studies (Li et al., 2004; Dickey and Strack, 2011; Steketee et al., 2012; Bertholet et al., 2013) reported that enhancement of mitochondrial fission was sufficient to induce major alterations in dendritogenesis and synaptogenesis of neurons in vitro. Here, we uncovered the fact that mitochondrial regulation of in vivo neuronal development is far more complex. Increasing mitochondrial fission accelerated dendritogenesis and spinogenesis only under conditions (exercise) that were associated with increased mitochondrial biogenesis. In exercise conditions, a massive increase in soma/dendritic shaft mitochondria was observed in immature neurons (16 dpi), which substantially ex- ceeded the soma/dendritic shaft mitochondrial content of mature neurons (28 and $106 \mathrm{dpi}$ ); concomitant Drp1 overexpression reduced the high mitochondrial content in the soma and dendritic shaft, increased the formation of globular mitochondria and the number of dendritic mitochondria, and most strikingly accelerated maturation. These observations indicate that coordination of mitochondrial fission and distribution with mitochondrial biogenesis is crucial for dendrite and spine development, and that fission and efficient dendritic distribution of the increased mitochondrial mass constitute limiting factors to exercise-induced maturation.

It was previously suggested that exercise induces the global enhancement of synaptogenesis and mitochondrial biogenesis in the dentate gyrus (Dietrich et al., 2008). As a consequence of lifelong neurogenesis, the DG harbors neurons, which are highly heterogeneous with respect to birth date and maturation stage. The retroviral labeling strategy allowed examination of the specific impact of exercise and of modulation of mitochondrial fission on DG neurons of defined developmental stages. Intriguingly, the effects of exercise alone or in combination with Drp1 overexpression on neuronal maturation as well as on growth and remodeling of mitochondria were highly prominent in young neurons (16 dpi), but were no longer present in more mature neurons (28 dpi). In a separate study, we also found that voluntary exercise did not affect dendrite morphology, spinogenesis, and mitochondrial parameters in 3-month-old adult-generated neurons (K. Steib and D. C. Lie, unpublished observations). These results are remarkable as they underline the exquisite sensitivity of immature adult-generated neurons to the voluntary exercise stimulus (Zhao et al., 2006; Piatti et al., 2011). Furthermore, our results indicate that the tempo of dendritic growth and the timing of spine formation are particularly sensitive to alterations in mitochondrial biogenesis, mitochondrial dynamics, and dendritic distribution. Last, the striking temporal correlation between exercise-induced morphological development and modification of the mitochondrial compartment strongly suggest that mitochondria mediate-at least in partthe effects of running on neuronal maturation. In this regard, it is noteworthy that exercise stimulates mitochondrial biogenesis in peripheral organs through pathways such as VEGF signaling and proliferator-activated receptor-gamma coactivator- $1 \alpha$ (PGC$1 \alpha$; Wright et al., 2008; Little et al., 2011), which have been implicated in the regulation of adult neurogenesis (Cao et al., 2004; Cheng et al., 2012).

How mitochondria regulate dendritogenesis and spinogenesis remains to be established. Mitochondria-dependent energy production is crucial for dendritogenesis, as illustrated by the dendritic growth defects following the impairment of mitochondrial ATP production (Oruganty-Das et al., 2012). In addition to energy production, mitochondria serve key functions in metabolism, biosynthesis, $\mathrm{Ca}^{2+}$ buffering, and signaling (McBride et al., 2006; Sekine et al., 2009). Synaptic compartments have particularly high demands for energy and $\mathrm{Ca}^{2+}$ buffering (Baloh, 2008; MacAskill et al., 2010), and there is in vitro evidence that mitochondria-dependent $\mathrm{Ca}^{2+}$ buffering influences the development of neuronal morphology (MacAskill et al., 2010; Dickey and Strack, 2011). Some data suggest that mitochondrial localization may be dispensable for neuronal development (Dickey and Strack, 2011). Yet, recent work not only revealed intricate mechanisms controlling mitochondrial positioning in dendrites and the axon, but also implicated mitochondria as an important local factor for establishing the topology of presynaptic and postsynaptic connectivity, probably through the regulation of local en- 
ergy supply and $\mathrm{Ca}^{2+}$ buffering (Li et al., 2004; Macaskill et al., 2009, 2010; Wang and Schwarz, 2009; Courchet et al., 2013). As mitochondrial biogenesis appears to occur close to the soma and requires fission of a larger mitochondrion into smaller mitochondria (O'Toole et al., 2008; Lovas and Wang, 2013), adequate mitochondrial supply of the developing axonal and dendritic compartment will be dependent on mitochondrial fission, which is in line with our present finding that mitochondrial fission constitutes a limiting factor to dendritogenesis and spinogenesis in adult neurogenesis.

Another important question is how coordination between mitochondrial function with signaling pathways, and transcriptional and epigenetic regulators of the development of adult-born neurons is achieved. The metabolic status regulates adult hippocampal neurogenesis (Knobloch et al., 2013) and can modify the activity of key developmental pathways (Saj et al., 2010). Hence, mitochondria-dependent metabolism itself may provide substantial input into the regulatory networks controlling different stages of adult neurogenesis. Neuronal activity-a potent regulator of transcriptional and epigenetic programs in adult neurogenesis (Jagasia et al., 2009; Ma et al., 2009; Hsieh and Schneider, 2013)—modulates mitochondrial dynamics and transport in vitro (Li et al., 2004; Han et al., 2008; Macaskill et al., 2009; Wang and Schwarz, 2009) and represents a candidate signal that coordinately controls genetic programs and mitochondrial function. Transcriptional programs downstream of neuronal activity may not only control the expression of neuron-specific genes but may also target mitochondrial biogenesis (Wong-Riley, 2012). In this regard, the transcription factor CREB-a key regulator of differentiation and maturation in adult neurogenesis (Merz et al., 2011) - may fulfill coordinative functions, given that its target PGC- $1 \alpha$ (Herzig et al., 2001) is considered to be the master regulator of mitochondrial biogenesis (Scarpulla et al., 2012) and has been linked to the control of spine maintenance in hippocampal neurons (Cheng et al., 2012).

Mitochondrial dysfunction is intimately linked to the pathophysiology of aging and neurodegeneration (Schon and Przedborski, 2011; Bratic and Larsson, 2013). The identification of mitochondrial function as an important player in adult neurogenesis raises the possibility that mitochondrial dysfunction may contribute to deficits in hippocampal neurogenesis-dependent cognition and suggests mitochondrial function as a candidate target to ameliorate cognitive impairment in aging and neurodegenerative diseases (Calingasan et al., 2008; Dietrich et al., 2008; Zhao et al., 2008; Cheng et al., 2010; Pieper et al., 2010; Voloboueva et al., 2010; Stoll et al., 2011; Voloboueva and Giffard, 2011; Mattson, 2012).

\section{References}

Aimone JB, Deng W, Gage FH (2011) Resolving new memories: a critical look at the dentate gyrus, adult neurogenesis, and pattern separation. Neuron 70:589-596. CrossRef Medline

Attardi G, Schatz G (1988) Biogenesis of mitochondria. Annu Rev Cell Biol 4:289-333. CrossRef Medline

Baloh RH (2008) Mitochondrial dynamics and peripheral neuropathy. Neuroscientist 14:12-18. CrossRef Medline

Beckervordersandforth R, Tripathi P, Ninkovic J, Bayam E, Lepier A, Stempfhuber B, Kirchhoff F, Hirrlinger J, Haslinger A, Lie DC, Beckers J, Yoder B, Irmler M, Götz M (2010) In vivo fate mapping and expression analysis reveals molecular hallmarks of prospectively isolated adult neural stem cells. Cell Stem Cell 7:744-758. CrossRef Medline

Bertholet AM, Millet AM, Guillermin O, Daloyau M, Davezac N, Miquel MC, Belenguer P (2013) OPA1 loss of function affects in vitro neuronal maturation. Brain 136:1518-1533. CrossRef Medline

Bracko O, Singer T, Aigner S, Knobloch M, Winner B, Ray J, Clemenson GD
Jr, Suh H, Couillard-Despres S, Aigner L, Gage FH, Jessberger S (2012) Gene expression profiling of neural stem cells and their neuronal progeny reveals IGF2 as a regulator of adult hippocampal neurogenesis. J Neurosci 32:3376-3387. CrossRef Medline

Bratic A, Larsson NG (2013) The role of mitochondria in aging. J Clin Invest 123:951-957. CrossRef Medline

Calingasan NY, Ho DJ, Wille EJ, Campagna MV, Ruan J, Dumont M, Yang L, Shi Q, Gibson GE, Beal MF (2008) Influence of mitochondrial enzyme deficiency on adult neurogenesis in mouse models of neurodegenerative diseases. Neuroscience 153:986-996. CrossRef Medline

Cao L, Jiao X, Zuzga DS, Liu Y, Fong DM, Young D, During MJ (2004) VEGF links hippocampal activity with neurogenesis, learning and memory. Nat Genet 36:827-835. CrossRef Medline

Cheng A, Hou Y, Mattson MP (2010) Mitochondria and neuroplasticity. ASN Neuro 2:e00045. CrossRef Medline

Cheng A, Wan R, Yang JL, Kamimura N, Son TG, Ouyang X, Luo Y, Okun E, Mattson MP (2012) Involvement of PGC-1alpha in the formation and maintenance of neuronal dendritic spines. Nat Commun 3:1250. CrossRef Medline

Courchet J, Lewis TL Jr, Lee S, Courchet V, Liou DY, Aizawa S, Polleux F (2013) Terminal axon branching is regulated by the LKB1-NUAK1 kinase pathway via presynaptic mitochondrial capture. Cell 153:15101525. CrossRef Medline

Dickey AS, Strack S (2011) PKA/AKAP1 and PP2A/B $\beta 2$ regulate neuronal morphogenesis via Drp1 phosphorylation and mitochondrial bioenergetics. J Neurosci 31:15716-15726. CrossRef Medline

Dietrich MO, Andrews ZB, Horvath TL (2008) Exercise-induced synaptogenesis in the hippocampus is dependent on UCP2-regulated mitochondrial adaptation. J Neurosci 28:10766-10771. CrossRef Medline

Frank S, Gaume B, Bergmann-Leitner ES, Leitner WW, Robert EG, Catez F, Smith CL, Youle RJ (2001) The role of dynamin-related protein 1, a mediator of mitochondrial fission, in apoptosis. Dev Cell 1:515-525. CrossRef Medline

Ge S, Yang CH, Hsu KS, Ming GL, Song H (2007) A critical period for enhanced synaptic plasticity in newly generated neurons of the adult brain. Neuron 54:559-566. CrossRef Medline

Han XJ, Lu YF, Li SA, Kaitsuka T, Sato Y, Tomizawa K, Nairn AC, Takei K, Matsui H, Matsushita M (2008) CaM kinase I alpha-induced phosphorylation of Drp1 regulates mitochondrial morphology. J Cell Biol 182:573585. CrossRef Medline

Herzig S, Long F, Jhala US, Hedrick S, Quinn R, Bauer A, Rudolph D, Schutz G, Yoon C, Puigserver P, Spiegelman B, Montminy M (2001) CREB regulates hepatic gluconeogenesis through the coactivator PGC-1. Nature 413:179-183. CrossRef Medline

Hsieh J (2012) Orchestrating transcriptional control of adult neurogenesis. Genes Dev 26:1010-1021. CrossRef Medline

Hsieh J, Eisch AJ (2010) Epigenetics, hippocampal neurogenesis, and neuropsychiatric disorders: unraveling the genome to understand the mind. Neurobiol Dis 39:73-84. CrossRef Medline

Hsieh J, Schneider JW (2013) Neuroscience. Neural stem cells, excited. Science 339:1534-1535. CrossRef Medline

Ishihara N, Nomura M, Jofuku A, Kato H, Suzuki SO, Masuda K, Otera H, Nakanishi Y, Nonaka I, Goto Y, Taguchi N, Morinaga H, Maeda M, Takayanagi R, Yokota S, Mihara K (2009) Mitochondrial fission factor Drp1 is essential for embryonic development and synapse formation in mice. Nat Cell Biol 11:958-966. CrossRef Medline

Jagasia R, Steib K, Englberger E, Herold S, Faus-Kessler T, Saxe M, Gage FH, Song H, Lie DC (2009) GABA-cAMP response element-binding protein signaling regulates maturation and survival of newly generated neurons in the adult hippocampus. J Neurosci 29:7966-7977. CrossRef Medline

Jessberger S, Aigner S, Clemenson GD Jr, Toni N, Lie DC, Karalay O, Overall R, Kempermann G, Gage FH (2008) Cdk5 regulates accurate maturation of newborn granule cells in the adult hippocampus. PLoS Biol 6:e272. CrossRef Medline

Knobloch M, Braun SM, Zurkirchen L, von Schoultz C, Zamboni N, AraúzoBravo MJ, Kovacs WJ, Karalay O, Suter U, Machado RA, Roccio M, Lutolf MP, Semenkovich CF, Jessberger S (2013) Metabolic control of adult neural stem cell activity by Fasn-dependent lipogenesis. Nature 493:226230. CrossRef Medline

Krzisch M, Sultan S, Sandell J, Demeter K, Vutskits L, Toni N (2013) Propofol anesthesia impairs the maturation and survival of adult-born hippocampal neurons. Anesthesiology 118:602-610. CrossRef Medline 
Li Y, Aimone JB, Xu X, Callaway EM, Gage FH (2012) Development of GABAergic inputs controls the contribution of maturing neurons to the adult hippocampal network. Proc Natl Acad Sci U S A 109:4290-4295. CrossRef Medline

Li Z, Okamoto K, Hayashi Y, Sheng M (2004) The importance of dendritic mitochondria in the morphogenesis and plasticity of spines and synapses. Cell 119:873-887. CrossRef Medline

Li Z, Jo J, Jia JM, Lo SC, Whitcomb DJ, Jiao S, Cho K, Sheng M (2010) Caspase-3 activation via mitochondria is required for long-term depression and AMPA receptor internalization. Cell 141:859-871. CrossRef Medline

Little JP, Safdar A, Benton CR, Wright DC (2011) Skeletal muscle and beyond: the role of exercise as a mediator of systemic mitochondrial biogenesis. Appl Physiol Nutr Metab 36:598-607. CrossRef Medline

Lovas JR, Wang X (2013) The meaning of mitochondrial movement to a neuron's life. Biochim Biophys Acta 1833:184-194. CrossRef Medline

Ma DK, Jang MH, Guo JU, Kitabatake Y, Chang ML, Pow-Anpongkul N, Flavell RA, Lu B, Ming GL, Song H (2009) Neuronal activity-induced Gadd45b promotes epigenetic DNA demethylation and adult neurogenesis. Science 323:1074-1077. CrossRef Medline

Macaskill AF, Rinholm JE, Twelvetrees AE, Arancibia-Carcamo IL, Muir J, Fransson A, Aspenstrom P, Attwell D, Kittler JT (2009) Mirol is a calcium sensor for glutamate receptor-dependent localization of mitochondria at synapses. Neuron 61:541-555. CrossRef Medline

MacAskill AF, Atkin TA, Kittler JT (2010) Mitochondrial trafficking and the provision of energy and calcium buffering at excitatory synapses. Eur J Neurosci 32:231-240. CrossRef Medline

Marín-Burgin A, Mongiat LA, Pardi MB, Schinder AF (2012) Unique processing during a period of high excitation/inhibition balance in adultborn neurons. Science 335:1238-1242. CrossRef Medline

Mattson MP (2012) Energy intake and exercise as determinants of brain health and vulnerability to injury and disease. Cell Metab 16:706-722. CrossRef Medline

McBride HM, Neuspiel M, Wasiak S (2006) Mitochondria: more than just a powerhouse. Curr Biol 16:R551-R560. CrossRef Medline

Merz K, Herold S, Lie DC (2011) CREB in adult neurogenesis-master and partner in the development of adult-born neurons? Eur J Neurosci 33: 1078-1086. CrossRef Medline

Ming GL, Song H (2011) Adult neurogenesis in the mammalian brain: significant answers and significant questions. Neuron 70:687-702. CrossRef Medline

Misaka T, Miyashita T, Kubo Y (2002) Primary structure of a dynaminrelated mouse mitochondrial GTPase and its distribution in brain, subcellular localization, and effect on mitochondrial morphology. J Biol Chem 277:15834-15842. CrossRef Medline

Oruganty-Das A, Ng T, Udagawa T, Goh EL, Richter JD (2012) Translational control of mitochondrial energy production mediates neuron morphogenesis. Cell Metab 16:789-800. CrossRef Medline

Osman C, Voelker DR, Langer T (2011) Making heads or tails of phospholipids in mitochondria. J Cell Biol 192:7-16. CrossRef Medline

O’Toole M, Latham R, Baqri RM, Miller KE (2008) Modeling mitochondrial dynamics during in vivo axonal elongation. J Theor Biol 255:369377. CrossRef Medline

Piatti VC, Davies-Sala MG, Espósito MS, Mongiat LA, Trinchero MF, Schinder AF (2011) The timing for neuronal maturation in the adult hippocampus is modulated by local network activity. J Neurosci 31 : 7715-7728. CrossRef Medline

Pieper AA, Xie S, Capota E, Estill SJ, Zhong J, Long JM, Becker GL, Huntington P, Goldman SE, Shen CH, Capota M, Britt JK, Kotti T, Ure K, Brat DJ, Williams NS, MacMillan KS, Naidoo J, Melito L, Hsieh J, et al. (2010) Discovery of a proneurogenic, neuroprotective chemical. Cell 142:39-51. CrossRef Medline

Sahay A, Wilson DA, Hen R (2011) Pattern separation: a common function for new neurons in hippocampus and olfactory bulb. Neuron 70:582-588. CrossRef Medline

Saj A, Arziman Z, Stempfle D, van Belle W, Sauder U, Horn T, Dürrenberger M, Paro R, Boutros M, Merdes G (2010) A combined ex vivo and in vivo RNAi screen for notch regulators in Drosophila reveals an extensive notch interaction network. Dev Cell 18:862-876. CrossRef Medline
Scarpulla RC, Vega RB, Kelly DP (2012) Transcriptional integration of mitochondrial biogenesis. Trends Endocrinol Metab 23:459-466. CrossRef Medline

Schon EA, Przedborski S (2011) Mitochondria: the next (neurode)generation. Neuron 70:1033-1053. CrossRef Medline

Sekine S, Miura M, Chihara T (2009) Organelles in developing neurons: essential regulators of neuronal morphogenesis and function. Int J Dev Biol 53:19-27. CrossRef Medline

Smirnova E, Shurland DL, Ryazantsev SN, van der Bliek AM (1998) A human dynamin-related protein controls the distribution of mitochondria. J Cell Biol 143:351-358. CrossRef Medline

Smirnova E, Griparic L, Shurland DL, van der Bliek AM (2001) Dynaminrelated protein Drp1 is required for mitochondrial division in mammalian cells. Mol Biol Cell 12:2245-2256. CrossRef Medline

Steketee MB, Moysidis SN, Weinstein JE, Kreymerman A, Silva JP, Iqbal S, Goldberg JL (2012) Mitochondrial dynamics regulate growth cone motility, guidance, and neurite growth rate in perinatal retinal ganglion cells in vitro. Invest Ophthalmol Vis Sci 53:7402-7411. CrossRef Medline

Stoll EA, Cheung W, Mikheev AM, Sweet IR, Bielas JH, Zhang J, Rostomily RC, Horner PJ (2011) Aging neural progenitor cells have decreased mitochondrial content and lower oxidative metabolism. J Biol Chem 286: 38592-38601. CrossRef Medline

Sun GJ, Sailor KA, Mahmood QA, Chavali N, Christian KM, Song H, Ming GL (2013) Seamless reconstruction of intact adult-born neurons by serial end-block imaging reveals complex axonal guidance and development in the adult hippocampus. J Neurosci 33:11400-11411. CrossRef Medline

Tashiro A, Zhao C, Gage FH (2006a) Retrovirus-mediated single-cell gene knockout technique in adult newborn neurons in vivo. Nat Protoc 1:3049-3055. CrossRef Medline

Tashiro A, Sandler VM, Toni N, Zhao C, Gage FH (2006b) NMDAreceptor-mediated, cell-specific integration of new neurons in adult dentate gyrus. Nature 442:929-933. CrossRef Medline

van Praag H, Christie BR, Sejnowski TJ, Gage FH (1999) Running enhances neurogenesis, learning, and long-term potentiation in mice. Proc Natl Acad Sci U S A 96:13427-13431. CrossRef Medline

van Praag H, Schinder AF, Christie BR, Toni N, Palmer TD, Gage FH (2002) Functional neurogenesis in the adult hippocampus. Nature 415:10301034. CrossRef Medline

Voloboueva LA, Giffard RG (2011) Inflammation, mitochondria, and the inhibition of adult neurogenesis. J Neurosci Res 89:1989-1996. CrossRef Medline

Voloboueva LA, Lee SW, Emery JF, Palmer TD, Giffard RG (2010) Mitochondrial protection attenuates inflammation-induced impairment of neurogenesis in vitro and in vivo. J Neurosci 30:12242-12251. CrossRef Medline

Wakabayashi J, Zhang Z, Wakabayashi N, Tamura Y, Fukaya M, Kensler TW, Iijima M, Sesaki H (2009) The dynamin-related GTPase Drp1 is required for embryonic and brain development in mice. JCell Biol 186:805816. CrossRef Medline

Wang X, Schwarz TL (2009) The mechanism of Ca2+-dependent regulation of kinesin-mediated mitochondrial motility. Cell 136:163-174. CrossRef Medline

Wong-Riley MT (2012) Bigenomic regulation of cytochrome c oxidase in neurons and the tight coupling between neuronal activity and energy metabolism. Adv Exp Med Biol 748:283-304. CrossRef Medline

Wright GL, Maroulakou IG, Eldridge J, Liby TL, Sridharan V, Tsichlis PN, Muise-Helmericks RC (2008) VEGF stimulation of mitochondrial biogenesis: requirement of AKT3 kinase. FASEB J 22:3264-3275. CrossRef Medline

Yaffe MP (1999) Dynamic mitochondria. Nat Cell Biol 1:E149-E150. CrossRef Medline

Zhao C, Teng EM, Summers RG Jr, Ming GL, Gage FH (2006) Distinct morphological stages of dentate granule neuron maturation in the adult mouse hippocampus. J Neurosci 26:3-11. CrossRef Medline

Zhao C, Deng W, Gage FH (2008) Mechanisms and functional implications of adult neurogenesis. Cell 132:645-660. CrossRef Medline 